\title{
Decision Usefulness: A re-examination of the information needs of nonprofit GPFR users
}

By

\author{
David J. Gilchrist ${ }^{1}$, Andrew West ${ }^{2}$ and Yuyu Zhang ${ }^{3}$
}

\begin{abstract}
The extent to which financial reports are decision useful is of central importance in relation to the accounting standards that underpin them. This is as true of nonprofit financial reporting as it is of financial reporting in the commercial and public sectors. In this paper we report on our findings related to a research project focused on examining the decision usefulness of Australian accounting standards from the point of view of nonprofit Users, Preparers and Auditors. Undertaking a series of round tables specific to each cohort, we examine the question of who is accountable, for what and to whom in the context of financial reporting. Our research reinforced a number of issues negatively impacting the ability of General Purpose Financial Reports to facilitate decision making in the nonprofit sector. However, we also identified a number of new issues related to financial reporting generally and current and prospective accounting standards specifically. Some of these phenomena appear to have manifested as a result of the impact of COVID and some of which are impacted by a changing funding environment. Overall, the project found that there are manifest specific issues and aspects which are particular to the sector and that need to be considered by standard setters in considering future frameworks and standards themselves.
\end{abstract}

Key Words: nonprofits, charities, accounting standards, financial reporting

\section{Acknowledgements}

The authors would like to acknowledge our colleague Dr Craig Furneaux who was instrumental in establishing this research project. We would also like to thank the Australian Accounting Standards Board for the opportunity to contribute our findings to the 2021 Research Forum and the advisors to the paper, Dr Ralph Kober and Dr Sabine Schuhrer, who provided insightful comments and suggestions. All errors and omissions are our own.

\footnotetext{
${ }^{1}$ Corresponding author: Not-for-profits UWA Research Team, University of Western Australia - david.gilchrist@uwa.edu.au

${ }^{2}$ School of Accountancy, Queensland University of Technology

${ }^{3}$ School of Accountancy, Queensland University of Technology
} 


\section{Decision Usefulness in Nonprofit Reporting Gilchrist, West \& Zhang}

\section{Introduction}

The Australian nonprofit sector is made up of approximately 600,000 incorporated and unincorporated organisations (Productivity Commission, 2010). Of these, charities are a subgroup that makes up approximately 56,000 organisations registered with the Australian Charities and Not-for-profits Commission (ACNC) and which form the basis of this paper given their generally more substantial regulatory and reporting obligations.

Nonprofits and charities can be incorporated in a variety of ways or not incorporated at all. Commonly they are incorporated associations under state/territory-based legislation, companies limited by guarantee under Commonwealth corporations legislation or perhaps historically incorporated under private acts of parliament often as related parties of churches. However, these organisations can also be incorporated as proprietary companies and co-operatives to give a further two examples - the issue is that their designation relates to their activities, mission and whether or not their foundation documents (e.g. constitution) allows them to distribute funds to their members as a profit share or on winding up. To be a nonprofit organisation, such distributions must be forbidden by the foundation documentation (Gilchrist, 2021).

In charities and nonprofit organisations, Those Charged With Governance can be referred to in a number of ways - committee members, directors, board members, trustees etc-depending on the type of incorporation and custom and practice within the organisation itself. In this paper, in order to simplify the narrative, we have used the term 'director' to refer to all of these possible usages.

Charities' obligations with regard to financial (and other) reporting are generally established via a tier system where they are described as Small, Medium or Large based on their annual turnover. ${ }^{4}$ Generally, the decision as to whether a charity is a reporting entity within the meaning of the Australian Accounting Standards is left to directors and, while not all charities must prepare General Purpose Financial Reports (GPFR), certain standards do have to be adhered to. Additionally, directors are not required to hold particular qualifications or experience though they must be appropriate persons to act in such a role. ${ }^{5}$

The Australian Accounting Standards are intended to support the decision usefulness of GPFR. These standards have been developed using the principle of transaction neutrality and, in this paper, we report on our findings developed out of a research project focused on the extent to which these standards support or prevent the effective use of financial reports for decision making. The research focused on discovering the perspectives of Users, Preparers and Auditors in relation to the level of decision utility they saw in financial reports based on the Australian Accounting Standards.

The research questions pursued were:

RQ1: Who is accountable? (Reporting Entity)

RQ2: To whom are nonprofits accountable? (Users)

RQ3: What information do users need? (Decision Usefulness)

RQ4: How is the information provided?

Overall, it was found that the participants were very supportive of the need for financial accountability and acquittal and saw audited financial reports as essential tools in achieving that outcome, notwithstanding the considerable experience and technical shortfalls identified in Users and Preparers. However, they also identified that there is unnecessary complexity in how some aspects of the reports are prepared - complexity that is exacerbated by shortfalls in User financial literacy, too many options in how elements might be prepared and presented, and some information shortfalls that should be added for nonprofit financial reporting but which have not traditionally been a component of GPFR reports. This last element was reinforced by the advent of COVID and particularly the crystallisation of employee costs that were not provided for. Additionally, it was found that the reported complexity likely has the effect of reducing interest in the reports themselves and promoting a culture of regulatory compliance rather than one of reporting enhancement, particularly in relation to directors.

\footnotetext{
${ }^{4}$ Small - Annual turnover less than $\$ 250,000$; Medium - annual turnover between $\$ 250,000$ but under $\$ 1$ million; Large, turnover of $\$ 1$ million or more.

${ }^{5}$ For instance, they cannot be bankrupts or criminals amongst other restrictions. See: https://www.acnc.gov.au/tools/factsheets/responsiblepersons-board-or-committee-members. See: https://www.acnc.gov.au/tools/topic-guides/responsible-persons
} 


\section{Decision Usefulness in Nonprofit Reporting Gilchrist, West \& Zhang}

Overall, there was cause to be positive in that the reporting process was universally supported and the process of improvement was one that drove the participants to contribute their time and experience to this project. Uniformly, participants agreed that financial reporting is important but that it is not working well. They also agreed that modifying standards combined with increased capacity within the Preparer and User cohort is worth pursuing. A longer-term view of standards development combined with education and support is likely to see improvements in the efficacy of financial reports developed by the nonprofit sector.

In this paper we have referred to nonprofit organisations and charities as nonprofits in order to simplify the narrative and maintain a view on the key themes. Further, we have capitalised the terms User, Preparer and Auditor in order to clearly refer to the participating cohorts while, if these terms are used without capitalisation, we are referring to the broader category.

This paper consists of seven sections. In section 2, we provide a brief overview of the literature relevant to this area and in section 3 we provide an overview of the methodology adopted and some relevant attributes of the participant cohort. In sections 4, 5 and 6 we respond to the research questions in turn and, in section 7, we provide concluding remarks.

\section{Literature Overview}

The extant literature relating to nonprofit financial reporting has been used to frame the research instrument used in this project and to identify issues that need to be explored in the context of this cohort.

The IFRS Foundation's (2018) Conceptual Framework for Financial Reporting is intended to provide consistency and understandability in accounting (para. SP1.1). It begins by framing the purpose of financial reporting in terms of providing information "that is useful to existing and potential investors, lenders and other creditors in making decisions relating to providing resources to the entity" (para. 1.2), and then describes these decisions as involving equity and debt instruments, loans and voting rights. While this may broadly capture the role of financial reporting in the for-profit private sector, it reflects organisational imperatives around financial resource management towards the maximisation of shareholder wealth. Yet organisations across the nonprofit sector are united by having missions and objectives that do not prioritise the maximisation of shareholder wealth.

On the face of it, therefore, there is reason to believe that the existing financial reporting standards and framework may not be appropriate for the nonprofit sector. Research has accordingly explored particular issues in financial reporting where difficulties or alternative accounting treatments for nonprofit organisations may be justified. These include recording volunteer contributions (Mook, Handy, \& Quarter, 2007; Mook, Sousa, Elgie, \& Quarter, 2005), and accounting for assets that have a restricted use or that may not have economic benefits (Rossouw, 2006, 2007, 2013). Ryan, Mack, Tooley, and Irvine (2014) draw upon these issues to suggest that an alternative conceptual framework that is specific to the nonprofit sector is necessary.

However, following the logic that financial reports should be oriented to the decision usefulness needs of Users, consideration ought to be given not only to problematic accounting issues, but also to who the users of nonprofit financial reports actually are, and what decisions they make. A stakeholder approach may consider all those affected by the organisation to be Users in some way (Dhanani \& Connolly, 2012; Evan \& Freeman, 1988), and in the context of charities, Hyndman and McDonnell (2009) specifically identified three categories of external stakeholders: Donors, Beneficiaries/Users and Regulators (see also Ryan et al. (2014)). Similarly, Gilchrist and Simnett (2019) observed that service recipients and communities may be more significant Users than members or providers of capital, but also pointed out that there are no definitive lists of Users for the sector.

Early empirical research on nonprofit Users focused on the usefulness for donors. Parsons (2003) provides an overview of work in this area, noting the importance of efficiency, effectiveness and financial stability for donors (see also Parsons' (2007) study on the impact of financial and non-financial information). Johansson, Carey, Tanewski, and Yusoff (2021) considered members of charities in particular, and through an analysis of annual reports concluded that the number of members is associated with the extent of reporting. They further argued that members are indeed a "salient stakeholder group" (p.5) and that "with more members, there is greater information asymmetry creating an incentive for more extensive annual report disclosures" (p.26). However, by analysing future revenue, Johansson et al. (2021) also suggested a link between performance information on charities and donors' decision making. 


\section{Decision Usefulness in Nonprofit Reporting Gilchrist, West \& Zhang}

Further, aligning with the expected User group identified for commercial entities, the literature has also identified employees, creditors, consumers of services and the broader community as what we term "assumed potential Users" of the financial reports as there is limited evidence extant that these groups are actual Users notwithstanding the logic of their inclusion in that category (Kilcullen, Hancock, \& Izan, 2007).

The study by Crawford et al. (2018) surveyed parties interested in nonprofit accounting and noted that, in an accountability context, different stakeholders were prioritised. Survey respondents considered accountability to external stakeholders (regulators / funders and then beneficiaries) to take priority over internal stakeholders (trustees / board members and then employees). They also noted that a stewardship perspective was considered more important than a decision usefulness perspective.

Given the prima facie case for sector specific accounting standards and guidance, a stakeholder approach to accountability, and varied empirical research that highlights the role of different stakeholder groups, there is a need for more targeted and in-depth investigation into User groups and their experience with nonprofit financial reporting. This study contributes to addressing this gap in the literature.

\section{Methodology \& Cohort Description}

We gathered information from semi-structured interviews with 30 participants made up of 13 Preparers, 12 Users, and 5 Auditors of nonprofit financial reports across Australia in 7 round table discussions held in July and August 2021. All the round tables were held using the Zoom platform with discrete groups of participants-that is, one round table of consisting of auditors, two of preparers and four of users. The preparers in the interviews were financial controllers or CFOs in nonprofit organisations, the Users were internal personnel including nonprofit chairs, CEOs or volunteer directors, and the Auditors were independent external auditors from audit firms or government audit bodies who are experienced in nonprofit auditing. Participants were recruited via an invitation email sent to CPA Australia members, the Institute of Community Directors members and to subscribers of the Not-for-profits UWA Research Team.

Table 1: Additional Descriptive Data Relating to Participants - Users and Preparers

Fifteen of the 30 participants were prepared to provide additional data related to their activities and organisations.

\begin{tabular}{|c|c|c|c|c|c|c|c|c|}
\hline $\begin{array}{l}\text { Participant } \\
\text { Category }\end{array}$ & $\begin{array}{l}\text { Participant Role in } \\
\text { Charity }\end{array}$ & Incorporation Style & Size & $\begin{array}{l}\text { Registered } \\
\text { Charity? }\end{array}$ & $\begin{array}{c}\text { State/ } \\
\text { Territory } \\
\text { Located }\end{array}$ & $\begin{array}{l}\text { City } \\
\text { Located }\end{array}$ & $\begin{array}{l}\text { Number } \\
\text { Members }\end{array}$ & $\begin{array}{l}\text { Annual } \\
\text { Audit? }\end{array}$ \\
\hline \multirow[t]{6}{*}{ Preparers } & $\begin{array}{l}\text { Executive Manager, } \\
\text { Corporate Services }\end{array}$ & Incorporated Association & Large & Yes & Victoria & Geelong & 30 & Yes \\
\hline & Finance Manager & Company Limited by Guarantee & Large & Yes & $\begin{array}{l}\text { Western } \\
\text { Australia }\end{array}$ & Perth & 9 & Yes \\
\hline & Operations Manager & Incorporated Association & Large & Yes & Queensland & Regional & 50 & Yes \\
\hline & $\begin{array}{l}\text { Corporate Services } \\
\text { Director }\end{array}$ & $\begin{array}{l}\text { Incorporated via Private Act of } \\
\text { Parliament }\end{array}$ & Large & Yes & $\begin{array}{l}\text { New South } \\
\text { Wales }\end{array}$ & Sydney & Unknown & Yes \\
\hline & Chief Finance Officer & Company Limited by Guarantee & Large & Yes & $\begin{array}{l}\text { New South } \\
\text { Wales }\end{array}$ & Regional & Unknown & Yes \\
\hline & Director & Company Limited by Guarantee & Small & Yes & Queensland & Brisbane & 130 & Yes \\
\hline \multirow[t]{9}{*}{ Users } & Director & Incorporated Association & Small & Yes & $\begin{array}{l}\text { Northern } \\
\text { Territory }\end{array}$ & Darwin & 50 & Yes \\
\hline & Business Manager & $\begin{array}{l}\text { Incorporated via Private Act of } \\
\text { Parliament }\end{array}$ & Large & Yes & $\begin{array}{l}\text { New South } \\
\text { Wales }\end{array}$ & Sydney & 2000 & Yes \\
\hline & CEO & Company Limited by Guarantee & Small & Yes & $\begin{array}{l}\text { New South } \\
\text { Wales / ACT }\end{array}$ & Canberra & 2 & Yes \\
\hline & Chief Operating Officer & Company Limited by Guarantee & Large & Yes & $\begin{array}{l}\text { New South } \\
\text { Wales }\end{array}$ & Sydney & 450 & Yes \\
\hline & CEO & Comp[any Limited by Guarantee & Large & Yes & $\begin{array}{l}\text { Western } \\
\text { Australia }\end{array}$ & Perth & 50 & Yes \\
\hline & CEO & Company Limited by Guarantee & Large & Yes & Queensland & Brisbane & Unknown & Yes \\
\hline & CEO & Company Limited by Guarantee & Large & Yes & $\begin{array}{l}\text { New South } \\
\text { Wales }\end{array}$ & North Ryde & 465 & Yes \\
\hline & Director & Company Limited by Guarantee & Large & Yes & $\begin{array}{l}\text { South } \\
\text { Australia }\end{array}$ & Adelaide & Unknown & Yes \\
\hline & Director & Incorporated Association & Large & Yes & Victoria & Melbourne & 634 & Yes \\
\hline
\end{tabular}

As such, Table 1 below provides additional data describing the preparer and user participants more fully. To maintain anonymity, we have not included information if disclosure might lead to their identification. 


\section{Decision Usefulness in Nonprofit Reporting Gilchrist, West \& Zhang}

With respect to auditors, three of the five auditors that participated were prepared to provide additional contextual information relating to their practice. Specifically, all three auditors were from non-Big Four firms but had more than two partners, between $60 \%$ and $100 \%$ of their client portfolios fell into the nonprofit sector, and they operated in New South Wales (Sydney), Victoria (Melbourne) and Queensland (various locations).

We organised the interviews in the form of round tables to encourage interaction and discussion among peer participants and to boost prompt feedback. There were seven 90-minute round tables of semi-structured interviews initially scheduled for groups of Preparers, Users, and Auditors respectively-no round tables were held where these participant types were mixed. To engage with additional Users, a supplementary round table was further organised with participants from different states/territories.

Semi-structured interviews were used to ensure that, in the first instance we were able to solicit responses to questions that led to us gaining an understanding with respect to what was top of mind for participants. We then gradually suggested issues and, ultimately, asked binary questions. This way we were able to elicit responses that were not prompted and then progress to prompted questions. The interview questions covered: top of mind responses from participants regarding their concerns relating to nonprofit financial reporting and associated accounting standards; their perceptions regarding the audience for financial reports and their information needs; general comments on the suitability of accounting standards for nonprofits and detailed comments on accounting standards relating to Assets, Liabilities, Financial Performance, and Presentation and Disclosure items; regulatory concerns; engagement concerns; and other issues, These discussions included cost/benefit concerns and valueadding discussions that participants considered significant in nonprofit financial reporting. The discussions were encouraged to expand in an organic way and specific questions were asked when the facilitator (one of the research team - all members of the research team attended at least one session) felt that the participants had exhausted their discussion points. Items of interest identified in one session were raised in subsequent sessions to assess relevance and to prioritise issues raised.

The participants were asked to think primarily about the nonprofit organisations for which they had worked, and further encouraged to share their general thoughts and comments in relation to nonprofit sector financial reporting. Anonymity and privacy were confirmed, and participants were advised that 'all examples given should be hypothetical if possible'. All the round table sessions were fully recorded. Ethical approval for the interviews were granted by the University of Western Australia.

\section{RQ1 - Who is accountable? (Reporting Entity)}

In this section we examine the evidence pertaining to Research Question 1: Who is accountable? We have equated this RQ with the Reporting Entity as we are focused on GPFR. However, we examine this research question by contextualising the responses relating to comments made regarding the capacity of directors to meet their responsibilities. We further examine the efficacy of accountability responses to assess the extent to which game playing occurs in order to manage stakeholders' potential responses to financial reporting.

The requirement for accountability to multiple stakeholders by the nonprofit and charitable sector was not contested by any participants. While the specific responsibilities of boards may be subject to dispute and the extent to which the accountability processes adopted (including in relation to financial reports) are effective, in the broader context the need for accountability is uniformly accepted. However, how that accountability may take shape with regard to financial reporting and how it is allocated to actors was a matter of discussion for all participants. At the highest level, this discussion highlighted a lack of understanding relating to the role of directors in financial reporting and reinforced some practices that might be seen as inappropriate from a governance perspective such as that directors were seen as Users of GPFR notwithstanding that the report is actually considered to be theirs in a strict governance sense. Overall, acceptance of the need for financial accountability was not accompanied by an understanding of how that financial accountability should be fulfilled - a lack of financial literacy and of governance experience and knowledge reinforced this finding and a lack of awareness was manifest regarding financial reporting within the User and Preparer cohorts. This lack of capacity manifests for a number of reasons including that directors interested in the purpose of the organisation were not necessarily seasoned governance practitioners, volunteer directors had unrelated professional backgrounds with limited experience of the industry the organisation operated in, and volunteer directors were retired and had not maintained currency:

“[Our committee members] are retired and have not been employed for twenty years" (User). 


\section{Decision Usefulness in Nonprofit Reporting Gilchrist, West \& Zhang}

With respect to regulatory compliance, almost all participants were of the opinion that this was both a major priority for their organisation and important for the personal comfort of Users and Preparers-it provides an impression as to how well the organisation is governed and how effectively it might operate. The principal regulators noted were the Australian Charities and Not-for-profits Commission (ACNC), the Australian Securities and Investments Commission (ASIC) and the Australian Taxation Office (ATO). However, participants, particularly Preparers, also noted their organisation's requirement to acquit to funders (in terms of government procurement and philanthropists) and discussed how the accounting standards and financial reports can affect their capacity to do so in particular relation to how the standards impact the "story" being communicated by the reports themselves and the impact of that story on the interpretation made by Users. There was expressed concern, for instance, that when a profit and/or cash reserves are reported, some readers of reports may consider that the reporting organisation does not need funding — whether from philanthropists or governments - as they have sufficient resources, notwithstanding the "story" told regarding mission-centric performance.

Furthermore, while the act of compliance was seen as critical, it was also noted by some participants across the three cohorts, that, often, the exercise is a "tick-the-box" exercise rather than an effective process that informs governance as well as those being accounted to. This came about because directors did not have sufficient financial literacy to use the reporting process more effectively and because of the pressures relating to financial resourcing as discussed above. Indeed, one User's observation is telling when describing the financial reporting and auditing process undertaken in his organisation:

"[We are]...on autopilot, to be honest, sort of rinse and repeat from last year, you know, from every previous year."

Another User was open in saying that their organisation was only interested in staying above the "boundary""[we want to] do enough to ensure the regulators don't come looking..." while yet another User indicated that, in their opinion, their organisation's members had sub-contracted the accountability responsibility to the auditor.

However, on a more positive note, the protection of an organisation's tax status was uniformly seen as critical with one User saying that "... [compliance] is the entry level for [for maintaining charitable status]" while audit costs are seen as "part of the deal". Reaffirming the universal acceptance that accountability was a fundamental expectation, Users, Preparers and Auditors were positively disposed to "getting it right" and ensuring financial reporting processes were appropriate to their purpose. Indeed, one User expressed the opinion that their organisation did not seek charity status as they did not want to be "beholden" to the regulators. The key issue here though was that the participants did not see utility in the reports beyond meeting regulatory requirements.

This concern manifested in two fundamental ways: (1) the Preparers and Users groups felt that the boards and committees of their organisations were also Users of the financial reports; and (2) there was a consistent and substantial confirmation across all participants that directors/committee members are not sufficiently well trained or experienced to understand the financial reports and the impact of accounting standards on them. This second element was almost universally accepted and reinforces the position of directors as Users.

The lack of financial expertise was also highlighted in the responses provided by Users and Preparers with regard to discussions pertaining to accounting standards themselves. Principally, preparers and CEOs reported that they typically had conversations with the board in which the management accounting results (which were reviewed on an iterative basis throughout the year) were reconciled to the financial report results usually focusing on the impact of accounting standards. Generally, boards were satisfied if the reconciliation was able to be explained and did not seek to discuss the impact of the standards on the nature of the information imparted by the report.

The issue of financial literacy pervades all responses to the Research Questions which are the focus of this research. However, with regard to RQ1 and who is accountable, the accepted role in ultimate accountability of directors is challenged directly if we accept the premise that financial literacy amongst the board and committee members of charities and Not-for-profits organisations is very low. This was highlighted by one preparer who said:

“...the predominant number of treasurers who assist the [organisation] do this without professional experience or certification" 


\section{Decision Usefulness in Nonprofit Reporting Gilchrist, West \& Zhang}

And reinforced by an Auditor who reported one board member as saying:

"We have a good accountant. She tells us what to do and we follow the instructions"

This comment was reinforced by participants in all three groups to the effect that directors are interested to know that the reports have been prepared and that solvency is not an issue but, otherwise, "... have no interest in finance" (Preparer) as they are there to support the mission of their organisation. This was confirmed by one Preparer who based their claim on the lack of engagement and minimal responses/queries raised by directors in their organisation.

Finally, the Auditors were in agreement that, while experience and technical capacity are significant constraints on the ability of directors to be accountable, there is insufficient funding provided to support administrative processes. In order to be effective in meeting accountability requirements, as one Auditor put it: "[organisations have] gotta have extra money [in order to] worry about it".

Overall, we identify three fundamental issues associated with accountability and the financial reporting process for NFPs: (1) financial literacy deficiencies likely mean that the financial reporting process is a much less effective governance tool than may be thought; (2) the principal accountable person in practice appears to be the CEO/CFO reporting to the board and to regulators; and (3) regulators and other Users of financial reports serve to reinforce and perpetuate the situation due to a lack of understanding regarding financial sustainability for NFPs. There also appears to be a significant need for education in order to increase financial literacy across all Users and potential Users, including government procurers and policy makers. Such an increase in understanding is likely to result in a more nuanced appreciation of the purpose, processes and importance of financial reporting and, therefore, of the accounting standards themselves. This outcome is also likely to cause more boards to question their reporting processes and more non-accountants to respond to consultative processes developed by the AASB to explore standards and proposed improvements.

\section{RQ2 - To whom are nonprofit organisations accountable? (Users)}

In this section, we examine the perspective communicated by participants relating to RQ2: To whom are nonprofit organisations accountable? It was noted above that there was universal agreement that NFPs are accountable to the ACNC, ASIC and the ATO. It was also universally agreed that financial resource providers (government procurers and philanthropists) are important consumers of accountability outputs, including financial reports together with the members of nonprofit organisations.

Members are an obvious group of Users with a significant interest in the organisation's sustainability. However, it was universally accepted that the vast majority of members are insufficiently financially literate to act as an effective responder to financial reports particularly in the context of their governance role. Further, the phrases reproduced above, regarding lack of financial literacy in directors, were thought to apply equally to membersthis is also logical given that, often, the directors are selected from the pool of members and are likely to have similar experiential attributes. Preparers also considered that the lack of feedback from members regarding financial reports was indicative of a lack of interest in them. Indeed, one User indicated that "people just want to know [the organisation] has money to pay the bills" while another simply said that the reports "... are not read by anyone".

Additionally, some Users, Preparers and Auditors indicated that while members are an important audience for accountability, they are not always empowered by the constitution sufficiently to have an impact. On the other hand, it was also reported that, where the constitution was too empowering, the financial reports could be "weaponised"- that is, the financial reports were used to attack the volunteer directors of the organisation. An additional issue raised was that some organisations do not have members other than the board members themselves and that this is a governance weakness. Even if they exist, in line with the previous section's discussion, these members are not likely to have sufficient skills and experience to act as an effective check on directors. Therefore, the quality of financial reports may not be challenged by members due to a lack of skills or a lack of power.

Funders were also considered to be a natural User group. Consisting of government agencies procuring services and supports, and of philanthropists, this group of Users was top-of-mind for Preparers and Auditors primarily because the resources provided by them were considered critical to organisational sustainability. However, as with the comment regarding members' interest, a Preparer also commented that their financial reports had received little response from funders which was taken as an indication of a lack of interest. 


\section{Decision Usefulness in Nonprofit Reporting Gilchrist, West \& Zhang}

It was curious to the researchers that philanthropists and government agencies were considered to be Users given their ability to command the production of financial information - that is, if nonprofits want to access funding, it is logical that they would need to acquiesce to the funder's information requests. However, upon being asked about this issue, Preparers indicated that philanthropists and government agencies use the financial reports as a form of triaging. That is, before asking for any additional information, these funders review the financial reports and then proceed to next steps if they are comfortable with the report itself. An example reported was in relation to tender processes - a much used procurement framework by governments - wherein those responding to the tender are almost universally required to provide audited financial reports with their submission. As such, Preparers were very insistent that financial reports were critical to their commencing a funding relationship even if specific information would be commended in the operation of the relationship.

Directors were identified as Users by some Preparers but also by some Auditors. In fact, one Preparer claimed that "... [they] rated directors as the most important Users of financial reports" with another saying they were the "gatekeeper for the board". This is a concerning finding, but it also reconciles with the comments made above regarding directors' and committee members' financial literacy levels and the impact these have on the ability of the financial reporting process to be effective. It also raises concern related to the extent to which directors can really acquit the responsibilities that are assumed to be within their purview. On a more positive note, one User indicated that the audited financial report was used by the board to "confirm the management reports" that they had been receiving throughout the year. However, it was telling to hear Preparers describe their role as one which "directs the auditor and board" as to what information goes to whom and that the CFO "drives the auditors". Some Preparers and Auditors indicated that some boards did not interact with the auditor at all. Overall, this finding reinforces the need for education if directors are going to have the governance role intended.

Some participants also identified partner organisations as Users of financial reports where the reporting organisation works with these partners to deliver services. The development of formal partnerships is an increasing phenomenon within the sector as government funding arrangements increasingly aim to provide fund allocation decision making to service users (Gilchrist, 2020b). Principally, Preparers reported that these partner organisations are provided financial reports when requested rather than the reporting organisation being proactive in providing this information regularly. However, Preparers also indicated that calls for financial reports from partner organisations is becoming more common which may see the more regular unsolicited provision of GPFR to such partners in the future.

Somewhat paradoxically, some Preparers indicated that they were Users too as they were very interested in the reports prepared by their colleagues in the industry and sought to compare their organisation's performance with the performance reported by others. They also wanted to compare the structure and content of their financial reports with those of other organisations. Primarily this appeared to be a need in the context of the competition for scarce philanthropic and government funding - "anything you can do to demonstrate best [practice in] governance the better" (Preparer) and "It helps to compete [for donor money when you produce] GPFR". The issue of comparability is discussed in the next section below.

Ad hoc reporting, or the use of the financial reports in response to ad hoc requests for information were also identified as responses to Users. Such ad hoc reporting could relate to potential funders, government agencies and other interested parties requesting general information pertaining to the NFP. Indeed, some Preparers and Auditors indicated that government agencies were increasingly inclined to seek information during the year rather than await the audited report such that Preparers indicated they are providing more quarterly and halfyearly information that included financial and non-financial data. Auditors indicated that banks also have a need for this information in the context of establishing lines of credit. In this respect, the utility inherent in the ACNC search facility and the data held by that agency, together with the financial reports submitted, was reported by Preparers to be important as a source of information in support of due diligence where needed and to "get to know" another organisation. It was also thought to be a good source of financial data for comparative purposes by those Preparers. However, those same Preparers indicated that they thought the ACNC Annual Information Statement (the method by which the ACNC collects regulatory data) did not hold data that always represented the reality. For instance, estimates may be entered instead of actual results and the limited ability to classify data meant that it may be too high level for meaningful analysis to be undertaken.

Finally, although certain Users (creditors, service users, staff) could be expected to have an interest in the financial performance of the entity, these cohorts were not top of mind for Preparers. Nevertheless, they did report that one effect of the COVID pandemic has been that staff and services users have become a more 


\section{Decision Usefulness in Nonprofit Reporting Gilchrist, West \& Zhang}

important actual audience as they have sought information pertaining to the going concern status of the organisation employing them or providing services to them. In other words, COVID has acted as a catalyst to realise these potential Users and create an audience of interest to Preparers where previously it was simply referred to as a "likely audience" by practitioners and within the literature.

\section{RQ3 - What information do users need? (decision usefulness)}

While financial information is necessary (e.g. Jones, Romano \& Smyrnios 1995; Staubus 2000), whether it is prepared and presented in a manner that is sufficient to meet all users' of nonprofit disclosures, needs to be examined (AASB 2017; Laughlin 2008, 2011; Ryan et al. 2014). In this section we review the data gathered in order to respond to RQ3: What information do Users need? In doing so, we have organised this section by theme rather than by User cohort and consider the broad issues preventing effective communication to Users as well as what has been described as necessary. That is, we have considered the responses to questions regarding problematic accounting treatments and responses pertaining to the accounting information that may be added to financial reports in support of better outcomes for Users.

While the external reporting process was identified as a costly process by Preparers-one preparer reporting that their organisation had income of approximately $\$ 1 \mathrm{~m}$ with financial management and reporting costs of $\$ 80,000$ to $\$ 90,000$ - no participants thought that it was unnecessary. Rather, they were concerned with the cost benefit calculus and the content of the reports so that they are fit for purpose, especially in the context of the need to report at a corporate level and also acquit at a program level - exercises that added significantly to the cost. This included the need to prioritise mission above financial reporting for at least one User who indicated that “...having good books doesn't mean [the organisation] has done a good job”. Perhaps unsurprisingly, one Auditor never-the-less reinforced the need for GPFR position by arguing that the accounting standards themselves are critical in order to ensure a true and fair view are presented.

The Users, Preparers and Auditors were also concerned about the term 'profit', indicating that the word's use is likely to imply that grants or other financial support is not needed. There was considerable concern across the cohorts with respect to the interpretation of the financial reports from a philanthropist's or government funder perspective. Nearly all participants raised concerns regarding the interpretation made by these Users when organisations presented financial reports that included reporting a profit and/or cash reserves. The principal concern being that funders would react by withholding financial resources because "....the organisation doesn't need them" (Preparer) and so "you don't want it to look good" (Preparer). Thus, there is an educative priority here with respect to Users understanding the need for profit and what not being profitable means for program and organisational sustainability.

Additionally, the Users, Preparers and Auditors were all of the opinion that this lack of understanding regarding profit and reserves drives financial decisions and budget decisions designed to ensure the organisation does not report a strong profit at the end of the year. These processes include bringing forward expenses and creating reserves. This finding is consistent with the findings of Gilchrist et al (2021) with regard to the financial reports of charitable disability service providers - not only was earnings management present but it was also focused on providing a financial report that included a break even result or a small loss — while commercial reporting entities are more likely to focus on earnings management techniques designed to increase apparent profit, NFPs are more likely to undertake similar processes in order to reduce apparent profit.

Preparers reported that many comments or queries received from Users related to the allocation of overheads to projects/programs - “...they care about whether the money is spent in accordance with the budget” (Preparer). This is a level of specificity that is usually not included in GPFR. Indeed, while large donors were considered to be more financially literate, they were also thought to be more interested in financial and performance outcomes of specific programs. This was reinforced by the uniform observation that a considerable amount of reporting and accounting resource is taken up in acquitting specific programs and projects, with costs increasing as a result of Preparers' time away from other priorities and audit requirements set by funders.

Preparers also reported that there is increasing interest from funders in obtaining reporting information focused on performance rather than financial outcomes. That is, outcomes measurement and performance measurement were of greater importance while the financial reports and audit report were simply underlying reports necessary to provide funders comfort. Preparers reported that the growing number of outcomes-focused contracts between government agencies and nonprofits represents an increasing risk, confirming findings in other studies (Gilchrist, 2020a) that governments lack experience and training in the identification, measurement and reporting of program outcomes. This translates into poor contracting which in turn impacts the ability of the 


\section{Decision Usefulness in Nonprofit Reporting Gilchrist, West \& Zhang}

funded organisation to report effectively. However, while Auditors agreed that this phenomenon was extant, there were difficulties with compliance due to a lack of: (1) data; (2) analytical capacity within nonprofits; and (3) a lack of assurance over the nonfinancial data used to prepare reports.

Finally, all cohorts reported a need for comparability. In line with the Preparers' reported responses to competitive pressure and funding scarcity, comparability between like organisations was seen as a priority, thus reinforcing the need for GPFR. However, in examining these comments more deeply, participants also revealed a concern that the current standards provide "...too many choices" (Preparer) reducing the opportunity for comparisons between entities. Another Preparer said that these options increased "flexibility" in reporting and noted that the opportunity for applying subjectivity "dilutes" the comparability between organisations. However, the Preparers and Auditors also reported that variability was enhanced as a result of funder requirements for additional program-specific reporting.

The cohorts all reported that variability in reports combined with complexity to reduce the understanding of Users and increase risks to nonprofits of the type described above, where funders baulk in providing resources due to extant profits or reserves. The complaint regarding excessive complexity was cited in relation to AASB15 and AASB 1058 which were used as examples by Preparers and Auditors to demonstrate that these standards added complexity without advantage to Users. For instance, the requirement to recognise income from grants or procurement processes where the outcomes related to the purpose of the funding were not sufficiently clear to allow for the staged recognition as the expenses were incurred, was uniformly raised as a significant issue. Preparers and Auditors indicted that Users and directors did not understand the logic and that organisations' resourcing opportunities were threatened due to apparent profitable performance. Notwithstanding one Auditor feeling that substance over form required an adherence to the current state of play, there was very significant support amongst Users, Preparers and Auditors for a return to the Matching Principle in order to remedy this situation on the basis that Users and directors could understand it better and that it was more easily communicated, particularly to funders.

The recognition of income issue applied to the receipt of capital funds for the purchase of assets too. Accounting for these funds as income was almost uniformly condemned on the basis that such recognition also tended to distort the apparent financial performance of the entity. No suggestions were posited with respect to a remedy for this issue though it occupied some discussion time in each session. Likewise, the issue of when to recognise bequests was raised by Preparers and Auditors alike. These funds, when paid, served to misrepresent the financial performance of the entity while recognition itself was also an issue. For instance, one Preparer reported that their organisation's auditor required the organisation to report bequest funding when the will was read-the Preparer was not sure whether this was the appropriate timing for recognition, whether the achievement of probate was the most appropriate timing or whether actual payment was most appropriate. After some discussion, it was agreed amongst that group of Preparers that payment was the most appropriate timing as many wills are contested when a bequest is made, and it is typical for charities not to contest relatives for the distribution.

On the other hand, in relation to the recognition of income, one Auditor observed that there was a social policy opportunity which is poorly understood by standard setters. That is, this auditor considered that, if governments, philanthropists and nonprofits can focus accountability on outcomes and delivery of services rather than utilising the matching principle, there would be an opportunity for prioritising the mission over financial reporting proclivities. However, as some Preparers observed, both the literacy issue and the complexity issue could be mitigated by a reversion to simpler accounting standards. In that sense, perhaps an intermediary step is warranted - one that reintroduces the matching principle but within the context of an education program aimed at Preparers and Users.

Additional complexity and cost were closely identified with the valuation of Long Service Leave and Annual Leave. The cohorts uniformly agreed that these elements needed to be reported and that Users understood the rationale for their inclusion in financial reports. However, the Preparers and Auditors also identified the cost of preparation as being prohibitive while the output was not necessarily considered an enhancement of reported information. One Preparer indicated that they felt that the exercise "...does not add value" while one Auditor reported that a client routinely uses the same formula to value Long Service Leave without revision. Again, these instances increase User confusion and serve to undermine the value of the reports in the Users' eyes, thus potentially mitigating any advantage achieved in issuing technically correct financial reports.

The valuation issue was raised with respect to assets as well. Both Preparers and Auditors reported the complexity associated with valuation of assets that were donated and the impact that valuation had on the profit 


\section{Decision Usefulness in Nonprofit Reporting Gilchrist, West \& Zhang}

and loss report - the constant concern with presenting a profitable outcome to Users - as well as the balance sheet. Valuation of what might be termed "specific purpose assets" - those assets that are peculiar to the nonprofit's operations such as churches or nature reserves-also represented a problem in that there were no clear ways to undertake this process and the initial donation or allocation to a nonprofit impacts the profit and loss to, in the words of one Preparer, "misrepresent profit". Finally, the recognition of a profit on sale of assets was also identified as problematic given the issue of Users' sensitivity with respect to profits-one Preparer confirmed that they revalue and then process the sale of an asset to avoid what is seen as an unhelpful impact on the financial report. While no solution was proffered here, one Auditor did say that they encourage their clients to be conservative in valuations.

In terms of complexity preventing engagement with financial reports, AASB 16 relating to leases was also uniformly identified as overly complex and of limited value in the nonprofit context. Indeed, one Preparer posited that the "...leasing [standard] is not useful". Another Preparer indicated that the explanation required to non-accountants on their board served to reduce the interest of directors and to reduce the veracity of the financial reports in their eyes. One Auditor reinforced this comment and suggested that it was necessary for there to be a commitment to an education process related to leasing reporting (and other complexities) prior to their implementation for this sector. That is, it is not about whether a treatment is technically right but whether the apparent complexity and/or difficulty in understanding actually reduces the impact of the report overall thus reducing the cost/benefit balance away from the ideal.

The issue of complexity and lack of understandability extended to the matter of consolidation and all cohorts felt that consolidated accounts were of limited value to Users. This argument was based on two considerations, firstly that the Users were interested in the individual organisations and consolidated statements were not transparent in that respect. Secondly, explaining the consolidation process to directors and resource providers was a fraught process that reduces the effectiveness of the financial reports overall as engagement wanes with a lack of understanding. On the other hand, one Auditor also observed that we need to consider the broader motivation for avoiding consolidation which includes avoiding damaging funding opportunities.

With respect to additional or different information, a number of issues were raised, and we turn to those now. All cohorts identified that there are material advantages to being able to present information in the financial report related to volunteer time consumed and donated goods. The lack of presentation of what one User termed "significant pro bono support" served to misrepresent the financial performance of the organisation and failed to demonstrate to Users "[...how] fine the line is between profit and loss". This failure also meant that some volunteers might feel undervalued in terms of their contribution, that directors and the CEO did not have the ability to present the organisation's complete resource requirement for advocacy purposes and that assets and projects were potentially undervalued where a component of value built in relates to unreported volunteer time.

Preparers and Auditors confirmed their view that providing a choice regarding reporting this element reduced comparability, but they also felt that the standards provided limited explanatory material and worked examples, both of which might enhance the take up of not only this reporting element but enhance understanding and application. Preparers also confirmed that there would be a cost to this process in that, potentially, new data would need to be collected, though there was some contention here as volunteer numbers and data are already required to be reported under the ACNC's Annual Information Statement arrangements. Further, it is generally recognised that it is important to ensure volunteers are identified as contributors from a recruitment and retention perspective.

Another area where improvement might be made and which gathered almost uniform agreement amongst all cohorts was that of distinguishing between "administered" and "controlled assets", otherwise termed "restricted" and "unrestricted" assets. While this issue was not top of mind for any participant, upon questioning it was identified as a reporting issue potentially negatively affecting the ability of the User to assess solvency and/or financial sustainability. While the issues was acknowledged uniformly, there was considerable difference with respect to what an appropriate mitigation might be. Regardless of participants' reflection that it is unlikely that Users read the notes to account, there was a significant majority of participants supporting the addition of a note to the accounts that separated these two forms of asset. Only a few participants agreed that separating these two asset types on the face of the Balance Sheet would add value from a User's perspective. One Preparer suggested that those assets held that were restricted in nature could be recognised by a contingent liability note. This is technically a logical consideration given that one Auditor emphasised the need to consider the likelihood that restrictions might be imposed. However, again, this does suggest that Users read the notes when the cohorts all agreed that they probably did not. 


\section{Decision Usefulness in Nonprofit Reporting Gilchrist, West \& Zhang}

Additionally, one Preparer thought the Australian Accounting Standards could provide methods for calculating administration expense and marketing expense ratios, while an Auditor felt that such ratios would increase comparability and decrease complexity while ensuring funders do not misunderstand the costs in a competitive funding marketplace.

The impact of COVID was also noted by some Preparers and Auditors in relation to sick leave and personal leave, two leave categories that are not entitlements nor accrued as prospective expenses, but which are increasingly cumulative and constitute material amounts. Additionally, many participants reported that the risks associated with these leave types were crystalised as a result of COVID but are becoming much more likely to be realised as the workforce ages. As such, COVID served to bring this issue forward and it was felt that its disclosure would provide a better reflection of the financial position of the reporting entity. However, the question of valuation was not responded to by participants.

Additional comments surrounding financial reporting generally included that Preparers thought that reporting on financial stability was important while others considered that the volume of notes to the accounts was excessive. There were no real alternative financial reporting methods reporting in the context of the overall picture of sustainability and outcomes. However, there were some ideas posited with respect to additional information that would likely assist the Users to understand the position and performance of the entity more effectively.

Having viewed the issues above around effective financial reporting, we reiterate that there was support across all cohorts for reducing the complexity of the preparation process even at the cost of technical correctness, that the reduction in choice would enhance the informational value of the reports to Users and that the addition of accruals relating to leave provisions that have not been recognised up to this time would all positively impact the benefit of the financial reports. As reported above, this could be supported by the Australian Accounting Standards by adding more specific and relevant examples to the standards to assist Preparers to prepare and explain the financial reports. These examples would both limit options for variance and explain the methodology. Indeed, one Preparer thought that the Australian Accounting Standards could include specific formula for valuation calculations, net present value calculations and leave provisions while another went further and said that the ACNC should issue the annual discount factor to be used for valuation purposes.

\section{RQ4 - How is the information provided?}

In this section we analyse the evidence from round tables related to how the information is provided and, more interestingly perhaps how it might be provided in the future. As such, here we respond to RQ4: How is the information provided? However, we also discuss comments made regarding what potentiality there is for change in the way information is provided.

In the first instance, it is clear that the predominant style of presenting financial information is via GPFR or SPFR. As such, one of the questions asked of Preparers related to whether their organisation published General Purpose Financial Reports of Special Purpose Financial Reports. In all, 53\% of organisations represented by Preparers reported that they published GPFR, 35\% reported they published SPFR while $12 \%$ were not sure. Of the Auditors, one indicated that $90 \%$ of their nonprofit client base published GPFR and this was replicated by another participant in the auditor cohort. The other Auditors were unsure as to the percentage but reported that the instances of clients preparing GPFR were increasing. One Auditor indicated that the high proportion of GPFR preparing clients was due to a material extent to the persuasion of the Auditor themselves. That is, while the reporting entity decision resides with directors, the Auditor indicated that the decision was made in the affirmative because auditors were advising their clients to adopt GPFR.

Almost all participants cited that their organisation — confirmed by Auditors — published summarised and often visually interesting financial information on their organisational websites. While their organisation may have produced GPFR, they do not publish those documents and, usually, only provide them when requested. To confirm this, a number of Preparers also indicated they rarely print more than a few copies of the document in hard copy, preferring to disseminate the reports via email or in downloadable format. One Preparer indicated that they thought a truncated and simplified audit report would add value to these published summaries but there was limited interest in this idea. Therefore, the organisations have made the decision that they are indeed reporting entities but still did not see value in publishing their GPFR. 


\section{Decision Usefulness in Nonprofit Reporting \\ Gilchrist, West \& Zhang}

\section{Concluding Remarks}

Overall, the need for financial reporting and assurance over that process was not challenged. Rather, the contents of the report and the cost/benefit associated with the preparation and presentation in accordance with the accounting standards was questioned with suggestions made for areas where improvement could be made. Additionally, the lack of capacity amongst Users and Preparers was also an aspect that underpinned responses relating to technical correctness. Therefore, the utility inherent in the standards was a matter of significance in relation to key preparation and presentation issues.

Building on that theme, complexity was cited as a significant issue both in terms of adding cost to the reporting process and in causing a decrease in engagement amongst directors and other Users. In terms of mitigations, one suggestion identified that a trade-off might achieve a better outcome with technical correctness being subordinated to understandability in the context of a longer-term process of skills building and communications.

More specifically, the participants identified a number of areas where nonprofit-specific accounting guidance might be more useful. These included in relation to the recognition of income relating to capital grants and bequests which, in the participants' minds are likely to mislead Users (especially funders) and increase the risk of funder withdrawal on the basis that funding is not needed. Additionally, the impact of COVID saw the identification of a need to recognise costs such as sick leave which are increasingly cumulative from an industrial perspective and, in the context of COVID and an ageing workforce, were identified as increasingly likely to be realised. Further, the participants also reported that the valuation of for-purpose assets and the recognition of volunteered time and donated goods were important shortfalls in terms of communicating the comprehensive cost of service delivery but also recognised the challenge in valuing and accounting for these elements these elements.

Finally, some Preparers and Auditors reported that there is opportunity for developing nonprofit-focused solutions which would include a reduction in options for preparation and reporting to enhance comparability and the addition of nonprofit-specific worked examples.

Overall, next steps are to evaluate these findings in the context of the current AASB research priorities and to assess the extent to which solutions are able to be applied in the current standards - using AUS Paragraphs for instance — or whether separately published and nonprofit-styled standards should be published. While the outcome is to achieve standards that meet the cost-benefit calculus in a positive way, attention is once again drawn to the suggestion that simplicity may be prioritised ahead of technical correctness in order to build capacity in the Users and Preparers and then to raise the bar with respect to technical correctness as education and experience grows. Therefore, it may be logical to develop a set of sector-specific standards in order to avoid the complexity structuring current standards that meet the short-, medium- and longer-term objectives. 


\section{Decision Usefulness in Nonprofit Reporting \\ Gilchrist, West \& Zhang}

\section{Bibliography}

Crawford, L., Morgan, G. G., \& Cordery, C. J. (2018). Accountability and not-for-profit organisations: Implications for developing international financial reporting standards. Financial accountability \& management, 34(2), 181-205. doi:10.1111/faam.12146

Dhanani, A., \& Connolly, C. (2012). Discharging not-for-profit accountability: UK charities and public discourse. Accounting, Auditing \& Accountability Journal, 25(7), 1140-1169. doi:http://dx.doi.org/10.1108/09513571211263220

Evan, W. M., \& Freeman, R. E. (1988). A Stakeholder Theory of the Modern Corporation: Kantian Capitalism. In T. Beauchamp \& N. Bowie (Eds.), Ethical Theory and Business (3rd ed., pp. 97-106). Upper Saddle River, NJ: Prentice-Hall.

Gilchrist, D. (2020a). All the Best Intentions: A Review of a Sub-National Attempt at Reshaping the Not-forprofit/Public Sector Nexus. In T.-T. S. Andrew Podger, John Wanna, Hon. S. Chan, and Meili Niu (Ed.), Designing Governance Structures for Performance and Accountability: Developments in Australia and Greater China. Canberra: Australian National University Press.

Gilchrist, D. (2020b). Silver Bullets and TED Talks: Sketching Ideas on the Government/Not-for-profit Nexus in the Australian Welfare State. Third Sector Review, 26(2), 20.

Gilchrist, D. J., Liu, Z. F., \& Etheridge, D. (2021). Earnings Management in Australian Not-for-profit Disability Services. SSRN. doi:http://dx.doi.org/10.2139/ssrn.3864804

Gilchrist, D. J., \& Simnett, R. (2019). Research horizons for public and private not-for-profit sector reporting: moving the bar in the right direction. Accounting and finance (Parkville), 59(1), 59-85. doi:10.1111/acfi.12439

Hyndman, N., \& McDonnell, P. (2009). Governance and charities: An exploration of key themese and the development of a research agenda. Financial accountability \& management, 25(1), 5-31. doi:10.1111/j.1468-0408.2008.00463.x

International Foundation for Accounting Research. (2018). Conceptual framework for financial reporting. IFRS Foundation.

Johansson, E., Carey, P., Tanewski, G., \& Yusoff, I. (2021). The effect of members on charities' annual reporting: evidence from companies limited by guarantee in Australia. Accounting and finance (Parkville). doi:10.1111/acfi.12842

Kilcullen, L., Hancock, P., \& Izan, H. Y. (2007). User Requirements for Not-For-Profit Entity Financial Reporting: An International Comparison. Australian Accounting Review, 17(41), 26-37. doi:10.1111/j.1835-2561.2007.tb00451.x

Mook, L., Handy, F., \& Quarter, J. (2007). Reporting Volunteer Labour at the Organizational Level: A Study of Canadian Nonprofits. Voluntas, 18(1), 55-71. doi:10.1007/s11266-007-9030-Z

Mook, L., Sousa, J., Elgie, S., \& Quarter, J. (2005). Accounting for the value of volunteer contributions. Nonprofit management \& leadership, 15(4), 401-415. doi:10.1002/nml.79

Parsons, L. M. (2003). Is Accounting information from Nonprofit organizations useful to donors? A review of charitable giving and value-relevance. Journal of Accounting Literature, 22, 104-129.

Parsons, L. M. (2007). The Impact of Financial Information and Voluntary Disclosures on Contributions to Notfor-Profit Organizations. Behavioral Research in Accounting, 19, 179-196.

Productivity Commission. (2010). Contribution of the Not-for-Profit sector. Retrieved from Canberra: https://catalogue.nla.gov.au/Record/4801854

Rossouw, J. (2006). Accounting requirements for donor-imposed restrictions and the restricted funds of not-forprofit organisations. Meditari Accountancy Research, 14(2), 33. doi:10.1108/10222529200600011

Rossouw, J. (2007). Recognition of restricted receipts by not-for-profit organisations: problems, standards and empirical results. Meditari Accountancy Research, 15(1), 71. doi:10.1108/10222529200700005

Rossouw, J. (2013). The need for specific accounting principles for non-profit organisations' assets without economic benefits, restricted donations and funds. Journal of Economic and Financial Sciences, 6(2), 459-478. doi:10.4102/jef.v6i2.270

Ryan, C., Mack, J., Tooley, S., \& Irvine, H. (2014). Do Not-For-Profits Need Their Own Conceptual Framework? Financial accountability \& management, 30(4), 383-402. doi:10.1111/faam.12044 